\title{
Volver a Pensar la Educación Pública ${ }^{1}$
}

\section{Juan Ansion}

\section{Pontificia Universidad Católica del Perú (PUCP)}

Juan Ansion es Doctor en Sociología por la Universidad Católica de Lovaina (Bélgica) y Profesor Principal de Antropología de la Pontificia Universidad Católica del Perú. Ha investigado y publicado sobre temas relacionados a cultura y antropología política, interculturalidad y educación. Actualmente está especialmente orientado a las propuestas de incorporación de la perspectiva intercultural en la educación universitaria. Es miembro de Foro Educativo y ha sido Presidente de la SIEP.

1 El texto que someto a consideración de los lectores fue escrito inicialmente para una seminario realizado en 2009 por la especialidad de sociología de la Pontificia Universidad Católica del Perú, que llevaba el título "(In)determinaciones entre lo público y lo privado en el Perú de hoy". La temática del seminario me pareció muy retadora para pensar la educación en el Perú. Me permitió hacer una revisión y un balance personal sobre el sentido que se dio a la educación pública en el contexto europeo de la llustración y posterior a ella, e intentar una comparación con el sentido que ha tenido en el Perú, todo ello a la luz de las graves brechas educativas que encontramos actualmente entre educación pública (o, más propiamente, estatal, en mi opinión) y educación privada en nuestro país. 


\title{
Volver a Pensar la Educación Pública
}

\begin{abstract}
Resumen
El texto se inicia con una discusión sobre el concepto de educación pública, recogiendo la perspectiva histórica desarrollada desde la llustración europea hasta las críticas de los teóricos de la reproducción y las dificultades actuales para replantear una visión optimista de la educación. En el Perú se acogió el término de educación pública, pero no en su sentido más democrático y moderno, sino como una manera de denominar a la educación estatal orientada hacia quienes no podían tener acceso a las escuelas destinadas a los hijos de las clases altas. El artículo muestra, a continuación, la realidad de la brecha entre educación estatal-pública y la educación privada, que se duplica también con la brecha entre educación rural y urbana. Esto encierra graves contradicciones que desfavorecen a todos y requieren ser enfrentadas social y políticamente.

Palabras clave: colegio público, acceso a la educación, democratización de la educación, discriminación educacional, Estado y educación
\end{abstract}

\section{Rethinking Public Education}

\begin{abstract}
The text begins with a discussion about the concept of public education from the historical perspective since the European Illustration until the theories of the reproduction, including the contemporaneous difficulties in creating an optimistic vision of education. In Peru, the term public education was not introduced in the more democratic and modern sense, but as a way of calling education by the state, this means education for people who have no access to schools of high class children. The article shows further the existing gap between public and private education and between rural and urban education. It shows great contradictions that are adverse for everyone and require to be confronted social and politically.
\end{abstract}

Keywords: public school, access to education, democratization of education, educational discrimination, State and education 


\section{Problematizando la Cuestión de la Educación Pública}

a noción de educación pública proviene de la llustración francesa que, con

ella, propugnaba "una educación dirigida a satisfacer las necesidades de la sociedad, y no de la Iglesia, una educación uniforme y laica bajo el manto del Estado", nos advierte de Puelles (2002, p. 23). Para los revolucionarios franceses, la educación apareció como una necesidad para todos los ciudadanos que, por tanto, constituye un derecho vinculado a la igualdad de todos. Para los jacobinos, la educación "no puede ser atributo de ningún estamento ni de ningún grupo social [...], de ahí que [...] deba ser asumida por el Estado" (de Puelles, 2002, p. 27). Esta concepción de la educación pública como equivalente de educación estatal es, sin embargo controvertida. Por ejemplo, en la "Crítica del Programa de Gotha", encontramos una visión de Marx generalmente desconocida -incluso para los marxistas - que critica duramente esa tendencia representada en la época por Lasalle. Así, Marx consideró absolutamente inadmisible una educación popular a cargo del Estado. Lejos de esto, indicaba, "lo que hay que hacer es substraer la escuela a toda influencia por parte del Gobierno y de la Iglesia [...] [y] es, por el contrario, el Estado el que necesita recibir del pueblo una educación muy severa" (Marx, s. f., p. 344).

De entrada, entonces, el tema de la relación del Estado con la educación y la ciudadanía aparece muy complejo. Ya en el siglo XVIII, Jean-Jacques Rousseau había pateado el tablero de los ilustrados. En su famoso "Emilio" contrapone dos tipos de institución, la pública y común, por un lado, y la particular y doméstica por la otra, y él opta claramente por la segunda. Nos presenta Esparta como ejemplo del desarrollo de la ciudadanía:

Una mujer de Esparta tenía cinco hijos en el ejército y esperaba noticias de la batalla. Llegó un ilota; ella le interrogó temblando. "Vuestros cinco hijos han muerto". "Vil esclavo ¿te he preguntado esto? ¡Hemos conseguido la victoria!" La madre corrió al templo, y dio gracias a los dioses. He aquí la ciudadana. (Rousseau, 1985, p. 39)

Ese antiguo dilema de la elección entre la ciudad y la familia ha sido representado genialmente en la tragedia griega: al elegir sepultar al hermano rebelde, Antígona se estaba condenando. Para Rousseau, en la época moderna, el dilema ha desaparecido: "Yo espero que se me presente este prodigio para saber si es hombre o ciudadano, o cómo se las compone para ser a la vez lo uno y lo otro" (Rousseau, 1985, p. 39) En efecto, para él “la institución pública 
no existe ya [...]. Estas dos palabras patria y ciudadano deben ser borradas de las lenguas modernas" (pp. 39-40). Y remata así la idea: "Yo no considero como una institución pública estos risibles establecimientos a los que se llama colegios" (p. 40). Lo que busca Rousseau es educar de acuerdo con lo que, siguiendo al ambiente intelectual de su tiempo, denomina el orden natural, en oposición al orden social o cívico. Y ese orden natural, diferente y opuesto al del bien público, es el orden doméstico. La educación orientada al desarrollo de ese orden natural y doméstico no apunta a preparar a las personas para que cumplan una función determinada en la sociedad, sino para que aprendan a vivir como hombres.

Casi un siglo y medio más tarde, Émile Durkheim inauguró la sociología de la educación afirmando lo opuesto de Rousseau:

Hablaré sobre todo de la educación moral de la segunda infancia en nuestras escuelas públicas; y les explico las razones. Es que, normalmente, las escuelas públicas son y deben ser el engranaje regulador de la educación nacional. [...] Si bien la familia puede efectivamente, y sólo ella, despertar y consolidar los sentimientos domésticos necesarios a la vida moral e inclusive, de manera más general, aquello que está a la base de las relaciones privadas más simples, ella no está constituida de manera a poder formar al niño con miras a la vida social. [...] Ahora bien, nos hemos comprometido a no dar a nuestras escuelas sino una educación moral enteramente racional $^{2}$. (Durkheim, 1934, p. 19)

Rousseau, siendo muy crítico de los precedentes autores del contrato social y de sus coetáneos de la llustración, seguía, sin embargo, inmerso en la problemática de la oposición entre naturaleza y sociedad. Al optar por educar al niño desde su naturaleza, rechaza hacerlo con fines sociales y ciudadanos. Curiosamente, el autor del "Contrato social" contrapone lo ciudadano con lo doméstico, la formación al servicio de la ciudad o del bien público con lo que llamaríamos la formación integral de la persona. El pensar en una educación para la vida es un gran progreso, siempre que no sigamos a Rousseau en contraponerla a una educación cívica.

Durkheim, a mi parecer, entendió bien la mutua relación entre vida social y vida personal. En los albores del siglo XX ya estaba roto el paradigma de la 
distinción entre naturaleza y sociedad y, para Durkheim, influenciado por la filosofía positivista de Auguste Comte, la vida social debía ser estudiada a la manera de un fenómeno natural (como una "cosa" objetivable). En ese contexto, y como heredero de la Revolución Francesa, la educación pública laica, orientada racionalmente y no por principios religiosos es la que, en su opinión, mejor se adecua a la sociedad moderna, a la sociedad de "solidaridad orgánica", aquella que con mayor fuerza ha desarrollado la especialización de sus integrantes. La educación, entonces, que es la "acción ejercida por las generaciones adultas sobre aquellas que todavía no están maduras para la vida social", tiene por objeto el

[...] suscitar y desarrollar en el niño un cierto número de estados físicos, intelectuales y morales que le reclaman tanto la sociedad política en su conjunto como el medio especial al que está particularmente destinado. (Durkheim, 2005, p. 51)

Todo el esfuerzo de Durkheim en "La educación moral" está encaminado a mostrar que lo social no se contrapone al individuo, ya que las reglas socialmente impuestas, si bien pueden ser a veces duras para el individuo, también pueden ser reconocidas y aceptadas libremente como tales por cada uno cuando tienen carácter racional. La educación pública, en esa perspectiva, es una educación orientada al bien público, al servicio de la sociedad en su conjunto y, por ese medio, al servicio también de cada uno de sus integrantes que reconocen la rectitud y racionalidad de las normas que la educación les ha impuesto.

Esta es, ciertamente, una visión muy optimista de la educación escolar, que no corresponde más a la que tienen en la actualidad los teóricos de la educación. En especial, después de las críticas de los teóricos de la reproducción, poco queda del entusiasmo de Durkheim, docente de La Sorbona en los albores del siglo XX. Para unos, la imposición de reglas se percibe como violencia simbólica (Bourdieu y Passeron, 1995); para otros, la especialización se identifica con la reproducción de las clases sociales (Baudelot y Establet, 1997) e, incluso, la institución escolar es presentada como un lugar donde los niños son "vigilados y castigados" de modo metódico, de un modo similar al de los presos en los "panópticos", cárceles de nuestros tiempos (Foucault 1990).

Ahora bien, estos críticos de la educación de fines del siglo XX no se interesaban fundamentalmente en la distinción entre la educación estatal y la educación privada dado que, para ellos - cada uno con sus matices-, la educación respon- 
día a estrategias de poder y de control por parte de las clases dominantes o de la cultura hegemónica. Todas las escuelas, más bien, aparecían como parte de la dominación de clase, como "aparatos ideológicos del Estado", según la expresión de L. Althusser, o como instrumentos de la "microfísica del poder" (Foucault, 1990). Desde luego, no todos comparten esta visión radical, pero el optimismo y la buena conciencia con respecto al papel de la escuela han sido seriamente puestos en cuestión sin que apareciera todavía con claridad una alternativa.

\section{La Educación Pública en el Perú}

En el Perú, el debate en torno a la escuela pública tomó un giro diferente. El énfasis se puso en la gratuidad de la educación. Así, la Constitución de 1933 la garantiza, aunque solo para la educación primaria ("obligatoria y gratuita"), ya que para la educación secundaria y superior solo se fomenta la "tendencia a la gratuidad". Aun con estas limitaciones, el tema de la gratuidad de la educación pública permanecerá en el Perú en las reivindicaciones sociales, como lo recuerda, por ejemplo, Degregori (1990), a propósito de las luchas por la gratuidad durante el gobierno militar de Juan Velasco que, en Huanta, terminaron con varios muertos.

El término "educación pública" asumido en el Perú recoge, entonces, el tema de la gratuidad, pero tiene un significado diferente de su origen francés. Recordemos que cuando apareció un ministerio dedicado específicamente a la educación, llevó el nombre de "Ministerio de Educación Pública". Es así como, en 1941, se promulgó la Ley Orgánica de Educación Pública № 9359, que sería derogada por la Ley General de Educación, Decreto Ley N¹9326, promulgada por el gobierno militar en 1972. En 1950, nos recuerda Elguera (s. f.), se publicó el Plan Nacional de Educación Pública, que confirmó esta denominación, que aún no se encontraba en la Constitución de 1933.

Los debates del Congreso Constituyente de 1932 nos dan algunas luces sobre el sentido que, en el Perú, se daría a la educación pública. Jorge Basadre describe el debate que ahí se produjo sobre los temas de educación. Después de recordar los puntos referidos a la gratuidad, y otros que serían aprobados, da cuenta de otro aspecto de la discusión particularmente pertinente aquí:

Revivió el agrio debate sobre el problema de la religión: Ricardo Feijóo Reyna ${ }^{3}$ propugnó el establecimiento de la escuela única, el monopolio de la 
enseñanza por el Estado, el laicismo de ella y la tecnificación de los organismos de la administración en este ramo. En el discurso que pronunció, atacó a los colegios particulares dirigidos por congregaciones religiosas extranjeras y a las características mismas del sistema imperante. También pidió la estabilidad en la carrera magisterial. Hildebrando Castro Pozo hizo la crítica de la educación primaria en el país. Víctor Andrés Belaúnde formuló la exposición de sus ideas que tenían el aval de los artículos respectivos insertos en el ante-proyecto de la comisión Villarán. Combatió la escuela única y la escuela laica y tuvo diálogos polémicos con Feijóo Reyna. El 13 de setiembre continuó la discusión. Alberto Arca Parró refutó a Belaúnde, atacó al clericalismo y defendió el laicismo y la escuela supervigilada por el Estado. Belaúnde, a su vez, le replicó y defendió a los colegios católicos y la libertad de enseñanza. Se le enfrentó en seguida Feijóo Reyna. Luciano Castillo fundamentó las ponencias socialistas. Rosendo Badani presentó interesantes datos estadísticos. B. Cevallos Chávez se definió como laicista y pidió la estabilidad magisterial contra el difundido vicio de los nombramientos, los traslados y las destituciones sin fundamento ${ }^{4}$. (Basadre, 1983, p. 265)

Está claro que estaba en juego el mantener la libertad de los colegios particulares frente al Estado, y estos, en esos momentos, estaban dirigidos por congregaciones religiosas extranjeras. Detrás de la cuestión religiosa, lo que se discutía era el derecho de los grupos sociales más acomodados de seguir educando a sus hijos en establecimientos que escaparan al control del Estado, mientras se buscaba incorporar a los sectores emergentes en instituciones gratuitas que permitirían el acceso de todos a la educación (por lo menos a la primaria), aunque dentro de una red diferente de la red religiosa y particular. Nótese que ya estaba vigente un problema que continúa hasta el día de hoy: la estabilidad de la carrera magisterial, que debería garantizar la racionalidad del sistema público-estatal.

Pero en la lucha social latinoamericana, especialmente en la lucha del magisterio, esta crítica intelectual no fue discutida ni mucho menos asumida. Siguió predominando la antigua idea de la defensa de la escuela pública como escuela estatal gratuita, como herencia de la idea lasalliana (más que marxista como lo hemos visto, pese a la autoidentificación como marxistas de muchos de sus 
defensores) y en la línea de la escuela pública y laica francesa que había sido también la base de la reflexión de Durkheim (aunque, ciertamente con énfasis en el carácter estatal de la educación más que en el carácter laico de la escuela).

Este proceso se entiende en un contexto en que la escolarización se iba convirtiendo en el gran medio de movilidad social. Pero la masificación de la educación es paralela a una educación privada destinada a las élites tradicionales, no solo étnicamente blancas, sino fuertemente vinculadas a colonias de países extranjeros y a sus sistemas educativos. Los teóricos de la reproducción han puesto en cuestión la ideología meritocrática que supone que, en el mundo moderno, el sistema escolar coloca a todos los niños frente a las mismas oportunidades y que, por tanto, el éxito educativo, y la posterior integración al mercado de trabajo, dependen de las capacidades y del esfuerzo de cada uno. En el Perú, podríamos decir que la dificultad por construir un sistema que iguale oportunidades es mayor que en otras partes por la existencia de estas dos redes - a estatal (Ilamada pública) y la privada - que están separadas por una profunda brecha. Las grandes unidades escolares fueron un esfuerzo insuficiente para superar esa brecha desde los años cincuenta. Y a principios de los años setenta, la Reforma de la Educación fue tal vez el intento más importante en ese sentido, pero el contexto de gobierno militar en el que se dio la condenó a ser abandonada con el retorno a la democracia 5 .

\section{Educación Estatal, Educación Privada}

Examinemos ahora algunas características muy generales de esa brecha. La primera constatación es que, en el Perú, el acceso a la educación escolar se ha masificado. Según cifras del Ministerio de Educación del año 2007, el 93,7\% de la población de 6 a 11 años se encuentra cursando la educación primaria. La educación secundaria alcanza a las tres cuartas partes de los niños $(74,6 \%$ de los niños de 12 a 16 años), mientras se mantiene un retraso en la cobertura de la educación inicial (64,2\% de los niños de 3 a 5 años).

Si se mira el tema ya no en términos de matrícula, sino de logros, se notan interesantes avances. Entre 2003 y 2007, la cifra global de culminación de la educación primaria subió de $72,5 \%$ a $77,6 \%$ entre 12 y 14 años, y de 91,8\% a

$5 \quad$ Es paradójico y revelador de la democracia en el Perú, que solo un gobierno militar haya tenido la voluntad política de reformar el sistema educativo para que se enfrentara a la brecha social existente. 
93,9\% entre 15 y 19 años, lo que indica que el problema, más que de presencia en el sistema, es de retraso escolar. Para la educación secundaria también se notan interesantes avances, con la misma previsible importancia del atraso escolar: se pasa de $51,3 \%$ a $60,3 \%$ entre 17 y 19 años y de $65,7 \%$ a $71,0 \%$ entre 20 y 24 años.

Veamos ahora la situación de la relación entre educación estatal y la educación privada en Lima. Tomando en cuenta los niveles de educación inicial, primaria y secundaria, la educación estatal y la privada representan respectivamente el $55 \%$ y el $44 \%$ del total de matrículas (Tabla 1 ).

Tabla 1

Alumnos Matriculados en el 2008 en Educación Estatal y Educación Privada en Lima (Provincia)

\begin{tabular}{lcccc}
\hline & \multicolumn{3}{c}{ Alumnos matriculados (2008) } \\
\cline { 2 - 5 } Nivel educativo & Educación estatal* & Educación privada & Total & $\begin{array}{c}\text { \% Educación } \\
\text { Privada }\end{array}$ \\
\hline Inicial & 138.874 & 168.911 & 307.785 & 55 \\
Primaria & 467.451 & 367.661 & 835.112 & 44 \\
Secundaria & 410.508 & 251.725 & 662.233 & 38 \\
Totales & $\mathbf{1 . 0 1 6 . 8 3 3}$ & $\mathbf{7 8 8 . 2 9 7}$ & $\mathbf{1 . 8 0 5 . 1 3 0}$ & $\mathbf{4 4}$ \\
\hline
\end{tabular}

Nota. Fuente: Censo escolar 2008 (Ministerio de Educación [MED], s. f.) - Elaboración propia.

*Incluye Municipios y Convenios.

Si se miran los mismos datos ya no desde el número de alumnos, sino desde el de las Instituciones Educativas (II. EE.), encontramos que las II. EE. privadas cubren el $78 \%$ en Lima (Tabla 2 ).

Tabla 2

Instituciones Educativas de Educación Estatal y Educación Privada en Lima (Provincia) en el 2008

\begin{tabular}{lcccc}
\hline & \multicolumn{4}{c}{ Instituciones Educativas (2008) } \\
\cline { 2 - 5 } Nivel educativo & Educación estatal* & Educación privada & Total & $\begin{array}{c}\text { \% Educación } \\
\text { Privada }\end{array}$ \\
\hline Inicial & 910 & 3.962 & 4.872 & 81 \\
Primaria & 935 & 3.352 & 4.287 & 78 \\
Secundaria & 651 & 1.745 & 2.396 & 73 \\
Totales & $\mathbf{2 . 4 9 6}$ & $\mathbf{9 . 0 5 9}$ & $\mathbf{1 1 . 5 5 5}$ & $\mathbf{7 8}$ \\
\hline
\end{tabular}

Nota. Fuente: Censo escolar 2008 (MED, s. f.) - Elaboración propia.

*Incluye Municipios y Convenios. 
La comparación entre las dos Tablas muestra con claridad que las escuelas privadas son, en promedio, mucho más pequeñas que las estatales: son 407 alumnos en promedio por I. E. estatal contra 87 por I. E. privada (Tabla 3).

Tabla 3

Alumnos Matriculados en el 2008 en Educación Estatal y Privada según Institución Educativa

\begin{tabular}{lcccc}
\hline \multirow{2}{*}{ Nivel educativo } & \multicolumn{2}{c}{ Educación estatal* } & \multicolumn{2}{c}{ Educación privada } \\
\cline { 2 - 5 } & $\begin{array}{c}\text { Número de II. } \\
\text { EE. }\end{array}$ & $\begin{array}{c}\text { Número de } \\
\text { alumnos por } \\
\text { II. EE. }\end{array}$ & $\begin{array}{c}\text { Número de II. } \\
\text { EE. }\end{array}$ & $\begin{array}{c}\text { Número de } \\
\text { alumnos por } \\
\text { II. EE. }\end{array}$ \\
\hline Inicial & 910 & 153 & 3.962 & 43 \\
Primaria & 935 & 500 & 3.352 & 110 \\
Secundaria & 651 & 631 & 1.745 & 144 \\
Totales & $\mathbf{2 4 9 6}$ & 407 & $\mathbf{9 . 0 5 9}$ & 87 \\
\hline
\end{tabular}

Nota. Fuente: Censo escolar 2008 (MED, s. f.) - Elaboración propia.

*Incluye Municipios y Convenios

\section{La Brecha Educativa}

En la relación entre educación estatal y educación privada, el problema central no está en quién es el dueño del servicio educativo, sino en que entre ambos canales se ha ido generando una brecha de calidad cada vez más insalvable. Esta profunda brecha se superpone a otra igualmente profunda entre la educación urbana y la educación rural. Esta segunda, casi exclusivamente de carácter estatal, está en nítida desventaja en comparación con la educación estatal urbana como lo muestran, por ejemplo las tasas de culminación de la educación secundaria que reporta el Ministerio de Educación hacia el año 2007: el 72\% de los estudiantes urbanos lo hacen entre los 17 y 19 años, mientras solamente del $36 \%$ de los estudiantes rurales de esas edades han culminado su secundaria.

Una evaluación de 2005 nos permite comparar cuantitativamente las diferencias de género, las que se dan entre instituciones educativas estatales y no estatales, así como las diferencias entre la educación urbana y la rural.

Observando los resultados en las Tablas 4 y 5, una primera constatación alentadora es que la brecha de género ya no aparece e, incluso, en el caso de la comprensión de textos, las mujeres tienen una ligera ventaja.

En cambio, la diferencia entre la educación estatal y la no estatal es muy grande, como se ve en el caso de la comprensión lectora y aun más en el 
desempeño lógico y matemático. Es catastrófico el hecho de que la mitad de los niños de escuelas estatales terminen su educación primaria sabiendo menos, en matemática, de lo que se consideran los conocimientos "previos" (es decir, previos a los conocimientos mínimos para tener oportunidad de aprender lo básico, que ni siquiera es el nivel de suficiencia). Esto significa que tendrán dificultades prácticamente insalvables para un posterior desarrollo en matemáticas.

La brecha entre la educación urbana y la rural es, de igual manera, absolutamente notoria. Ahí bastaría ver que más de la mitad de los alumnos de las escuelas rurales (que son también estatales) se encuentran por debajo del nivel previo en comprensión de textos y más del 70\% está ahí en pensamiento lógico-matemático. Resultados similares aparecen en la diferencia entre las escuelas polidocentes (en las que el maestro o la maestra tiene a su cargo un solo grado) y las multigrado (en las que el docente se hace cargo de varios grados). De ese modo, la diferencia rural urbano se superpone - para empeorarla- a la diferencia estatal-privado.

Tabla 4

Resultados Nacionales en Comprensión Lectora en $6^{\circ}$ grado de Primaria (2004)

\begin{tabular}{|c|c|c|c|c|c|c|c|c|c|}
\hline \multirow{3}{*}{$\begin{array}{l}\text { Niveles de } \\
\text { desempeño }\end{array}$} & \multirow{3}{*}{ Nacional } & \multicolumn{8}{|c|}{ Resultados en Comprensión Lectora (\%) } \\
\hline & & \multicolumn{4}{|c|}{ Nacional } & \multicolumn{4}{|c|}{ Estatal } \\
\hline & & Hombre & Mujer & Estatal & No estatal & Urbano & Rural & Polidocente & Multigrado \\
\hline Suficiente & 12,1 & 11 & 13,3 & 8,2 & 36,1 & 11 & 2,3 & 10,5 & 1,7 \\
\hline Básico & 28,1 & 28,1 & 28,2 & 26 & 40,9 & 32,8 & 11,8 & 31,6 & 10,5 \\
\hline Previo & 35,7 & 36,2 & 35,1 & 38,3 & 19,4 & 40,2 & 34,4 & 39,7 & 34,3 \\
\hline$<$ Previo & 24,1 & 24,7 & 23,5 & 27,5 & 3,5 & 16 & 51,5 & 18,1 & 53,5 \\
\hline
\end{tabular}

Nota. Fuente: Resultados de IV Evaluación Nacional de rendimiento estudiantil 2004 (Unidad de Medición de la Calidad [UMC], s. f.).

Tabla 5

Resultados Nacionales en Lógico Matemática en $6^{\circ}$ grado de Primaria (2004)

\begin{tabular}{|c|c|c|c|c|c|c|c|c|c|}
\hline \multirow{3}{*}{$\begin{array}{l}\text { Niveles de } \\
\text { desempeño }\end{array}$} & \multirow{3}{*}{ Nacional } & \multicolumn{8}{|c|}{ Resultados en Comprensión Lectora (\%) } \\
\hline & & \multicolumn{4}{|c|}{ Nacional } & \multicolumn{4}{|c|}{ Estatal } \\
\hline & & Hombre & Mujer & Estatal & No estatal & Urbano & Rural & Polidocente & Multigrado \\
\hline Suficiente & 7,9 & 9 & 6,8 & 4,4 & 29,7 & 5,8 & 1,3 & 5,6 & 0,9 \\
\hline Básico & 34,7 & 36,4 & 32,9 & 31,9 & 51,7 & 39,5 & 16 & 38 & 14,7 \\
\hline Previo & 12,7 & 12,7 & 12,6 & 13,6 & 7 & 15 & 10,6 & 14,7 & 10,4 \\
\hline$<$ Previo & 44,7 & 41,9 & 47,7 & 50,2 & 11,6 & 39,7 & 72,1 & 41,7 & 74 \\
\hline
\end{tabular}

62 Nota. Fuente: Resultados de IV Evaluación Nacional de rendimiento estudiantil 2004 (UMC, s. f.). 


\section{La opinión sobre Educación Estatal y Educación Privada}

La brecha entre educación estatal y educación privada que acabamos de observar se expresa de manera nítida en la opinión pública. El Instituto de Opinión Pública de la PUCP viene preguntando por tercer año consecutivo por la opinión sobre ambos tipos de educación, expresada en una "nota" puesta a la educación primaria y secundaria. Las Tablas 6 y 7 muestran los resultados obtenidos en las preguntas sobre la educación primaria. Las respuestas en el caso de la educación secundaria son similares.

\section{Tabla 6}

Pregunta: En los colegios los estudiantes son evaluados con notas del 0 al 20, donde 0 significa pésimo y 20 significa excelente. Si tuviera que ponerle una nota de 0 a 20 a la educación que se da en el Perú, ¿qué nota le pondría a la educación primaria que dan las escuelas estatales?

\begin{tabular}{|c|c|c|c|c|c|}
\hline \multirow{2}{*}{ Respuestas } & \multirow{2}{*}{$\begin{array}{c}\text { Marzo } \\
2007\end{array}$} & \multirow{2}{*}{$\begin{array}{c}\text { Febrero } \\
2008\end{array}$} & \multirow{2}{*}{$\begin{array}{c}\text { Febrero } \\
2009\end{array}$} & \multirow{2}{*}{\multicolumn{2}{|c|}{ Resumen 2009}} \\
\hline & & & & & \\
\hline De 0 a 4 & 4 & 4 & 7 & & \\
\hline De 5 a 8 & 16 & 12 & 13 & 38 & Hasta 10 \\
\hline De 9 a 10 & 17 & 23 & 18 & & \\
\hline De 11 a 12 & 28 & 26 & 24 & & \\
\hline De 13 a 15 & 25 & 26 & 30 & 61 & 11 y más \\
\hline De 16 a 20 & 6 & 7 & 7 & & \\
\hline No precisa & 3 & 3 & 3 & 3 & \\
\hline Total \% & 100 & 100 & 100 & 100 & \\
\hline $\begin{array}{l}\text { Base de entrevistas } \\
\text { ponderada }\end{array}$ & 449 & 533 & 481 & 481 & \\
\hline
\end{tabular}

Nota. Fuente: Encuestas del Instituto de Opinión Pública de la PUCP (Instituto de Opinión Pública [IOP], 2007, 2008, 2009).

Como se observa en los cuadros, en la última encuesta la educación primaria estatal sale desaprobada en un 38\%, contra un $7 \%$ para la educación privada. Este resultado es similar al de los años anteriores. La Tabla 8 nos informa acerca de la opinión sobre la preparación para buenos trabajos futuros, y ahí sí encontramos una diferencia en el último año, comparando con los años anteriores, que mostraría que la tendencia a no creer en las posibilidades de la escuela estatal se va consolidando. 
Tabla 7

Pregunta: En los colegios los estudiantes son evaluados con notas del 0 al 20, donde 0 significa pésimo y 20 significa excelente. Si tuviera que ponerle una nota de 0 a 20 a la educación que se da en el Perú, ¿qué nota le pondría a la educación primaria que dan las escuelas privadas?

\begin{tabular}{|c|c|c|c|c|c|}
\hline \multirow{2}{*}{ Respuestas } & \multirow{2}{*}{$\begin{array}{c}\text { Marzo } \\
2007\end{array}$} & \multirow{2}{*}{$\begin{array}{c}\text { Febrero } \\
2008\end{array}$} & \multirow{2}{*}{$\begin{array}{c}\text { Febrero } \\
2009\end{array}$} & \multirow{2}{*}{\multicolumn{2}{|c|}{ Resumen 2009}} \\
\hline & & & & & \\
\hline De 0 a 4 & 1 & 1 & 1 & & \\
\hline De 5 a 8 & 4 & 3 & 2 & 7 & Hasta 10 \\
\hline De 9 a 10 & 5 & 4 & 4 & & \\
\hline De 11 a 12 & 11 & 9 & 8 & & \\
\hline De 13 a 15 & 44 & 39 & 37 & 90 & 11 y más \\
\hline De 16 a 20 & 31 & 41 & 45 & & \\
\hline No precisa & 5 & 3 & 3 & 3 & \\
\hline Total \% & 100 & 100 & 100 & 100 & \\
\hline $\begin{array}{l}\text { Base de entrevistas } \\
\text { ponderada }\end{array}$ & 449 & 533 & 481 & 481 & \\
\hline
\end{tabular}

Nota. Fuente: Encuestas del Instituto de Opinión Pública de la PUCP (IOP, 2007, 2008, 2009).

Tabla 8

Pregunta: ¿Qué tan de acuerdo o en desacuerdo está usted con la siguiente afirmación: la educación que se brinda hoy en día en los colegios públicos prepara a los jóvenes a que consigan buenos trabajos en el futuro?

\begin{tabular}{lccc}
\hline Respuestas & Marzo & Febrero & Febrero \\
\cline { 2 - 4 } & 2007 & 2008 & 2009 \\
\hline $\begin{array}{l}\text { Muy de acuerdo / } \\
\text { De acuerdo }\end{array}$ & 34 & 33 & 26 \\
$\begin{array}{l}\text { En desacuerdo / } \\
\text { Muy en desacuerdo }\end{array}$ & 65 & 66 & 72 \\
$\begin{array}{l}\text { No precisa } \\
\text { Total \% }\end{array}$ & 1 & 1 & 3 \\
\hline $\begin{array}{l}\text { Base de entrevistas } \\
\text { ponderada }\end{array}$ & 100 & 100 & 100 \\
\hline
\end{tabular}

Nota. Fuente: Encuestas del Instituto de Opinión Pública de la PUCP (IOP, 2007, 2008, 2009).

Así, la respuesta a la baja calidad de la educación estatal (identificada 64 I con educación pública) parece razonable y se concreta en la preferencia por 
la educación privada. Esta idea, que se ha ido consolidando con el desarrollo de la ideología neoliberal y sus políticas, conduce en la práctica al abandono paulatino de la educación estatal porque pareciera que la educación privada constituye una buena alternativa. La mala situación de la educación estatal debería conducir a un cambio drástico, como el que exigen tanto el Acuerdo Nacional como el Proyecto Educativo Nacional - ambos importantes espacios de concertación educativa - cuando concuerdan en llegar progresivamente a dedicar el 6\% del Producto Bruto Interno (PBI) a la educación. Pero la posibilidad real de las familias de buscar una alternativa en la educación privada, aun cuando muchas veces no pueda concretarse, hace posible que se mantengan políticas que mantienen totalmente estancado el presupuesto educativo, en uno de los niveles más bajos de América Latina. Según Vexler (s. f.) seguimos alrededor del 2,8\% entre 2000 y 2005.

De ese modo, se mantiene un abismo entre las declaraciones políticas y las políticas educativas. Es mucho lo que se podría decir aquí. Un tema central es que, en la práctica, no se cumple con la política del Acuerdo Nacional y del Proyecto Educativo Nacional de ir avanzando progresivamente hacia la dedicación del $6 \%$ del PBI a la educación. Se mantiene, además, una política de confrontación con el gremio magisterial. No se enfrenta con seriedad la corrupción en el sector y no se da impulso a los órganos de decisión democrática previstos en la Ley General de Educación. De modo general, la política educativa real (no necesariamente la declarada) no se orienta por el espíritu del Proyecto Educativo Nacional. Con todo ello, se alienta a que los padres y madres de familia que puedan hacerlo saquen a sus hijos de los centros escolares estatales para colocarlos en centros educativos privados (no siempre de mejor calidad, por lo demás) para intentar dar a sus hijos un mejor futuro ante el abandono por el Estado de las escuelas a su cargo. Luego de varios intentos frustrados por privatizar la educación, esta política de abandono por parte del Estado conduce a un lento proceso de privatización en la práctica, proceso particularmente perverso porque es en gran medida invisible, porque no garantiza la calidad del servicio educativo y porque una privatización de ese tipo va, en general, en contra de una educación democrática orientada al bien público.

Al mismo tiempo, el país está a merced de iniciativas personales del presidente de la República, como la creación del "Gran Colegio Mayor Secundario de Perú", cuyo objeto es que los 500 mejores alumnos de secundaria del país, desde el tercer año, reciban una educación de excelencia en un internado cerca de Lima. De ese modo, algunos entre los niños con mejores rendimientos del 
país se beneficiarán, pero la inmensa mayoría quedará abandonada a su suerte, sin siquiera la posibilidad de interactuar con estos niños privilegiados.

Se ve entonces cómo una política que no apunta a cerrar la enorme brecha educativa existente conduce, por un lado, a una privatización solapada y, por otro, al revivir una idea anticuada, la de los colegios de excelencia, que solo apunta a mantener expectativas y a aparentar dar soluciones con miras electorales.

Pero, entonces, ¿cómo salir del atolladero? Y, en primer lugar, ¿cómo pensar hoy en día el tema de la brecha educativa?

\section{La Relación entre Equidad y Calidad}

Estudios internacionales recientes muestran que el tema de la calidad educativa no puede ser abordado independientemente del de la equidad. Un trabajo presentado por un equipo de la Universidad Autónoma de Barcelona (Constans, Ferrer y Ferrer, 2008) muestra que existe un estrecho vínculo entre equidad y excelencia. Luego de seleccionar 34 países en los que se tomó la prueba PISA (Programa Internacional de Evaluación de Estudiantes de la OCDE -Organización para la Cooperación y el Desarrollo Económicos-, aplicada ente 2000 y 2003 -en 2001 en el Perú-) que permite comparar las escalas de competencia de los escolares de esos países, compararon primero estos países en función del porcentaje de niños que alcanzan los niveles 4 y 5 (los mayores niveles) de la escalera de comprensión lectora. Mientras Finlandia, en un extremo, se acerca al $50 \%$ de sus alumnos ubicados en esos niveles, Perú tiene el peor récord de todos, alrededor del 1\%, muy por debajo, además, de otros países latinoamericanos como Brasil, Chile o México, que no alcanzan ni el $10 \%$. En América Latina, solamente Uruguay y Argentina tienen más del 10\% de sus alumnos en esos niveles.

Los autores crean un índice sintético complejo como indicador de equidad del sistema educativo que calcula la media de tres grupos de indicadores: indicadores de igualdad final de resultados, indicadores de igualdad de acceso a un nivel mínimo de resultados e indicadores de igualdad de oportunidades (Constans, Ferrer y Ferrer, 2008). Con este indicador, los países con mayor nivel de equidad, como Hong Kong, Canadá o Finlandia, obtienen resultados menores a -0,50. Los países latinoamericanos están todos entre los de menor equidad y obtienen resultados cercanos a $+1,00$ ó $+1,50$. Perú es el que el mayor nivel obtiene (es decir, el de menor equidad), con un índice de más de $+2,50$. 
Al cruzar los datos de porcentaje de alumnos en los niveles 4 y 5 de la escala de Comprensión Lectora con el indicador de equidad del sistema, se puede ver que los países con el mejor indicador de equidad (el de valor negativo) son también aquellos que lograron los mejores niveles de excelencia. El caso de Perú es desgarrador: tiene de lejos el peor indicador de equidad y el peor resultado en la prueba PISA.

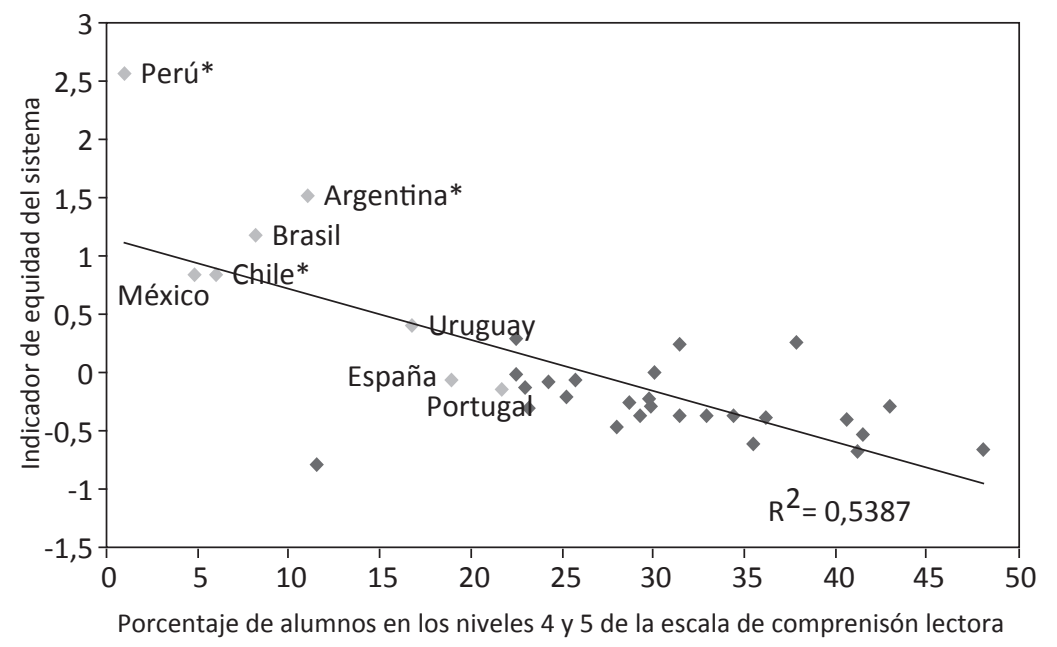

Figura 1. Excelencia y Equidad del Sistema Educativo. Fuente: datos obtenidos de base de datos de PISA 2000 y 2003 (Constans, Ferrer y Ferrer, 2008).

* Porcentaje obtenido de la base de datos de PISA 2000 (Constans, Ferrer y Ferrer, 2008).

Un estudio reciente de PREAL va en el mismo sentido (Barber y Mourshed, 2008). Aquí se analizan los sistemas educativos más exitosos: los 10 primeros puestos del Informe PISA de la OCDE y 7 sistemas educativos, nacionales o locales, con fuerte trayectoria de mejora. Las conclusiones son contundentes:

Todos los sistemas educativos que han experimentado importantes mejoras lo han logrado fundamentalmente porque han creado un sistema que es más eficiente en tres aspectos: conseguir gente más talentosa que se interese por la docencia, desarrollar a sus docentes para que sean mejores instructores y garantizar que estos instructores se 
brinden en forma consistente a todos los niños del sistema ${ }^{6}$. (Barber y Mourshed, 2008, p. 45)

Este tercer aspecto es crucial: la excelencia del conjunto depende de la capacidad del sistema de abarcar a todos y cada uno de los niños, de no dejar a ninguno rezagado.

Los sistemas educativos con alto desempeño [...] fijan altos objetivos a alcanzar por todos y cada uno de los niños, y luego monitorean su desempeño en comparación con las expectativas, interviniendo allí donde estas últimas no son satisfechas. Los sistemas educativos con alto desempeño intervienen eficazmente a nivel de cada escuela, e identifican aquellas que no tienen un desempeño satisfactorio con el objetivo de elevar los estándares de desempeño. Los sistemas de excelencia intervienen a nivel de cada alumno, y desarrollan dentro de las escuelas los procesos y estructuras capaces de identificar cuando un estudiante está comenzando a retrasarse, interviniendo para mejorar el desempeño del niño. (Barber y Mourshed, 2008, p. 38)

El prejuicio tendente a creer que los mejores estudiantes tienen que juntarse solo con los mejores va exactamente en el sentido contrario de estas recomendaciones. La educación de excelencia no pasa por la construcción de colegios que sean solo para los mejores, poco importa que sean de carácter privado o en manos del Estado. Este punto es de enorme importancia para las políticas y había sido advertido ya en los años sesenta en los Estados Unidos como consecuencia del debate sobre la gran encuesta realizada entonces y publicada en 1966 bajo el título significativo de "Equality of Educational Opportunity". Jean-Claude Forquin, recogiendo el debate, concluye con lo siguiente:

Una conclusión más específica se desprenderá de este informe, esto es, que el éxito de un alumno depende también en gran medida de las características del grupo-clase en el cual se encuentra, es decir de las características sociales, culturales, conductuales, de sus compañeros de aula. Es así como los alumnos de la minorías étnicas obtienen - manteniéndose iguales todos los demás factores-mejores resultados en aulas 
de composición variada que en aulas étnicamente homogéneas. Se sabe que este resultado de la investigación tuvo importantes consecuencias en los Estados Unidos, ya que contribuyó fuertemente, en nombre de la lucha contra la segregación, a motivar la llamada política del "bussing", es decir del transporte de alumnos de un barrio a otro con miras a asegurar una suerte de equilibrio multirracial en determinadas escuelas ${ }^{7}$. (Forquin, 1997, p. 18)

Pero, en el Perú, no se cree en la bondad de mezclar a niños provenientes de diferentes medios étnicos o socioeconómicos, y de ahí la persistente división entre escuelas estatales y privadas, con las múltiples y a veces sofisticadas distinciones dentro de cada uno de estos canales. Tampoco se cree en el valor de mezclar estudiantes con rendimientos académicos diferentes ( $y$, sin duda, también con una multiplicidad de talentos diversos y ocultos) y por ello, en las escuelas estatales, se sigue enviando a los "peores" alumnos a las secciones "C", "D", "E", en las cuales los docentes no esperan nada de ellos. La lógica del Gran Colegio Mayor Secundario, criticada ya líneas arriba, va exactamente en esa línea equivocada de separar a los "mejores" de los "peores".

Tampoco en el Perú se cree en un patrón común para todos. A manera de ejemplo, contaré una experiencia personal. Durante el gobierno actual de Alan García surgió una discusión a propósito de libros de Ciencias Sociales que formaban parte de un paquete comprado por el Ministerio de Educación para estudiantes de secundaria de colegios del Estado. Por un azar de las designaciones institucionales, me encontré, como docente de la Universidad Católica, formando parte de una comisión encargada de evaluar estos textos. Los puntos más álgidos giraban en torno a la interpretación de la época de violencia política y de la actitud de los diversos actores. Los miembros de la Comisión encontramos que el texto era bastante abierto e invitaba al debate, lo que nos pareció un mérito importante, con lo cual el informe fue favorable al libro. Pero el punto que quiero destacar es que el representante de los colegios católicos nos informó que este texto ya se había venido utilizando desde hacía varios años en el circuito privado sin problema ni objeción alguna. Mi conclusión es que el problema radicaba en que un libro de esta naturaleza fuera entregado a niños de sectores populares o de clase media baja (aquellos que no acceden a las escuelas privadas). ¿Acaso el miedo es que el pensamiento crítico llegue a

$7 \quad$ Traducción propia. 
estos sectores? El corte de la Reforma de la Educación de los años setenta iba ya en ese sentido en tanto esa reforma incentivaba abiertamente el espíritu crítico y la creatividad para todos (y no solo, desde luego, para los estudiantes de establecimientos privados).

\section{Conclusiones}

El concepto de educación pública en el Perú ha sido marcado por una historia en la que la educación masiva de los sectores pobres, originalmente indígenas, no tuvo el carácter revolucionario de la educación pública francesa, sino se fue desarrollando por presión social, paralelamente a otro tipo de educación orientada a las clases altas y encargada a instituciones privadas, sean estas de índole religiosa o vinculadas a identidades e intereses de países extranjeros.

La pujanza por la educación de los hijos, que fue uno de los grandes fenómenos sociales e ideológicos del siglo XX en el Perú, no se tradujo, al final, en una integración armoniosa de "todas las sangres" ni en nuevas jerarquías sociales basadas fundamentalmente en principios meritocráticos. La escolaridad en el Perú abrió ciertamente muchas nuevas oportunidades, pero no eliminó la antigua brecha social heredada del periodo colonial (por ejemplo, ver Figueroa, 2006). En ese sentido, la "educación pública" no fue aquella que el país desarrolla como bien público para todos, como "educación moral" que crea valores cívicos comunes a todos independientemente de sus orígenes sociales, étnicos o culturales, sino más bien como una educación supletoria brindada por el Estado para quienes no pueden pagar otro tipo de educación. Pese a momentos de la historia en los que produjo espacios de calidad (como las grandes unidades escolares en sus inicios), esta educación "pública" estatal siguió entonces y sigue siendo una educación "de segunda", una educación para pobres, muy diferente de la educación privada, sobre todo de la educación privada orientada a los sectores altos de la sociedad.

De ahí deriva una grave contradicción. La educación estatal constituye, sin duda, un importante servicio público al permitir la incorporación al sistema educativo de la mayoría de niños peruanos quienes, de otra manera, nunca tendrían acceso a él, pero, por otro lado, al aceptarse fácilmente la distinción marcada entre una educación que sería pública y otra que no lo es, se exacerba y reproduce la gran brecha colonial y poscolonial, impidiendo así que la escuela contribuya positivamente a la articulación de todos los peruanos, a 
su identificación como ciudadanos, independientemente de sus orígenes. Se reproducen así antiguas jerarquías étnicas, a las que se han ido sobreponiendo nuevas jerarquías producto del sistema educativo mismo.

En el presente texto he querido mostrar también otro aspecto central de esta contradicción. La separación radical entre educación estatal y educación privada no solo impide o, al menos, limita fuertemente la posibilidad del desarrollo de una ciudadanía moderna y democrática, sino también constituye una barrera estructural al mejoramiento de las competencias educativas en el país en general, es decir, también en los medios sociales más favorecidos. En contra de las ilusiones del sentido común, los estudios actuales muestran que, en materia de educación, todos los niños son interdependientes: si no se levantan todos, todos estarán en problemas serios. Por ello, la noción misma de colegio de excelencia, utilizada para construir el nuevo Colegio Mayor, o la de "colegios emblemáticos", está profundamente equivocada.

Así, en educación, solo acortando la brecha entre educación estatal y educación privada, y entre educación rural y urbana, se podrá levantar significativamente la calidad de la educación para todos y contribuir al desarrollo del país en su conjunto. Hemos llegado a una situación en la que se hace evidente que quienes dirigen el país tienen un interés limitado en la educación estatal, por lo menos, en parte, porque sus hijos estudian en instituciones educativas privadas. Ya es tiempo de revertir esta situación. Y una condición para ir poco a poco cerrando la brecha es desarrollar políticas agresivas de lucha contra toda forma de discriminación, particularmente por motivos étnicos. En ese sentido, la educación intercultural, que trabaja sobre la relación entre los diferentes para generar condiciones de convivencia en paz, constituye un camino privilegiado para generar un tipo de ciudadanía a la vez más inclusiva y más diferenciada.

La educación, en ese sentido, adquiere un sentido cívico y público para todos. Y la educación es pública no porque sea de propiedad del Estado, sino porque constituye un proceso en el que la sociedad participa desde los actores diversos de la escuela. Los consejos educativos institucionales o los municipios escolares, como estructuras de participación y de articulación de la sociedad previstos por la actual Ley General de Educación, constituyen piezas clave para ese proceso, siempre, desde luego, que se pongan en funcionamiento. Y el principio de la interculturalidad para todos nos invita a construir un país que empiece a aprender a manejar sus diferencias como riqueza para todos en lugar de ocasión para ahondar antiguas o nuevas brechas. 


\section{Referencias}

Barber, M. y Mourshed, M. (2008). Cómo hicieron los sistemas educativos con mayor desempeño del mundo para alcanzar sus objetivos. PREAL Documentos, 41. Recuperado de www.preal.org/publicacion.asp

Basadre, J. (1983). Historia de la República del Perú 1822-1933 (Tomo X) (7ma. ed.). Lima: Editorial Universitaria.

Baudelot, C. y Establet, R. (1997). La escuela capitalista. México, D.F.: Siglo Veintiuno.

Bourdieu, P. y Passeron, J. C. (1995). La reproducción: elementos para una teoría del sistema de enseñanza. México, DF: Laia.

Constans, M.; Ferrer, G. y Ferrer, F. (2008). Los sistemas educativos en Iberoamérica desde la perspectiva de la equidad y la excelencia. Análisis a partir del proyecto PISA y otros indicadores de sistema educativo. En J. E. García-Huidobro, V. Dupriez y G. Francia (Coords.), Políticas educativas en América Latina. ¿Transición hacia un nuevo paradigma? (pp. 97-120). México: Secretaría de Educación Pública.

Degregori, C. (1990). Ayacucho 1969-1979. El surgimiento de Sendero Luminoso. Del movimiento por la gratuidad de la enseñanza al inicio de la lucha armada. Lima: Instituto de Estudios Peruanos.

De Puelles, M. (2002). Estado y Educación: una relación histórica. En A. Ruiz (Coord.), La escuela pública: el papel del Estado en la educación (pp. 17-48). Madrid: Biblioteca Nueva,

Durkheim, E. (1934). L'éducation morale (Cours de sociologie dispensé à la Sorbonne en 1902-1903). París: Librairie Félix Alcan.

Durkheim, E. (2005). Éducation et sociologie. (9na. ed.) París: Quadrige/PUF.

Elguera, E. A. (s. f). Historia de la educación universitaria en el Perú. Recuperado de http://www.universia.edu.pe/_descargas/9/16/historia EduUniv.pdf.

Figueroa, A. (2006, septiembre). Education, labor markets, and inequality in Peru. Ponencia presentada en el Taller Latinoamericano de CRISE (Centre for Research on Inequality, Human Security and Ethnicity), en Santa Cruz.

Forquin, J. C. (1997). Les sociologues de l'éducation américains et britanniques. Présentation et choix de textes. París-Bruselas: De Boeck Université.

Foucault, M. (1990). Vigilar y castigar: nacimiento de la prisión (18va. ed.). Madrid: Siglo Veintiuno. 
Instituto de Opinión Pública. (2007). Estado de la opinión pública: educación. Recuperado de http://iop.pucp.edu.pe/images/documentos/2007\%20 MARZO\%20EDUCACION\%20LIMA.pdf

Instituto de Opinión Pública. (2008). Estado de la opinión pública: educación. Recuperado de http://iop.pucp.edu.pe/images/documentos/2008\%20 FEBRERO\%20EDUCACION\%20LIMA.pdf

Instituto de Opinión Pública. (2009). Estado de la opinión pública: educación. Recuperado de http://iop.pucp.edu.pe/images/documentos/2009\%20 Educaci\%C3\%B3n-\%20Febrero.pdf

Marx, C. (s. f.). Crítica del Programa de Gotha. En C. Marx y F. Engels, Obras escogidas. Moscú: Editorial Progreso.

Ministerio de Educación. (s. f.). Censo Escolar 2008 [estadísticas del Ministerio de Educación del Perú sobre Instituciones Educativas escolarizadas de menores (inicial, primaria y secundaria)]. Recuperado de http://escale. minedu.gob.pe/censo-escolar

Rousseau, J. J. (1985). Emilio o de la educación. Madrid: EDAF.

Unidad de Medición de la Calidad. (s. f.). Evaluación Nacional 2004 [resultados de la IV Evaluación Nacional de rendimiento estudiantil 2004 del Ministerio de Educación]. Recuperado de http://www2.minedu.gob.pe/umc/index2. php?v_codigo $=25 \&$ v_plantilla $=A$

Vexler, I. (s. f). Informe sobre la educación peruana. Situación y perspectivas. Recuperado de http://www.ibe.unesco.org/International/ICE47/ English/ Natreps/reports/peru.pdf

Manuscrito recibido: 10 de mayo, 2011

Revisado: 04 de agosto, 2011

Aceptado: 12 de septiembre, 2011 